\title{
PENGEMBANGAN EKOWISATA KAWASAN HUTAN DENGAN SKEMA HUTAN KEMASYARAKATAN DI DAERAH ISTIMEWA YOGYAKARTA (Development of Forest Area Ecotourism with Community Forest Scheme in Daerah Istimewa Yogyakarta)
}

\author{
Indah Novita Dewi ${ }^{*}$, San Afri Awang ${ }^{2}$, Wahyu Andayani ${ }^{2}$, dan Priyono Suryanto ${ }^{2}$ \\ ${ }^{1}$ Program Doktoral Studi Ilmu Kehutanan, Fakultas Kehutanan, Universitas Gadjah Mada, \\ Jl. Agro No. 1 Bulaksumur, Yogyakarta, 55281 \\ ${ }^{2}$ Fakultas Kehutanan, Universitas Gadjah Mada, Jl. Agro No.1 Bulaksumur, Yogyakarta, 55281 \\ *Penulis korespondensi. Tel: 085242025185. Email: indahnovitadewi@yahoo.com \\ Diterima: 1 Februari 2016 \\ Disetujui: 11 Mei 2017
}

\begin{abstract}
Abstrak
Pengembangan Hutan Kemasyarakatan $(\mathrm{HKm})$ oleh pemerintah bertujuan untuk pemberdayaan dan peningkatan pendapatan masyarakat. HKm dapat dilaksanakan di area hutan produksi maupun hutan lindung. Petani HKm hutan lindung harus dapat mengembangkan potensi selain hasil kayu, salah satunya potensi wisata. Tulisan ini bertujuan untuk mengungkap peluang dan tantangan pengembangan ekowisata di kawasan HKm hutan lindung di Daerah Istimewa Yogyakarta. Penelitian dilakukan tahun 2014 di kawasan HKm Kulon Progo maupun Gunungkidul. Data dikumpulkan melalui metode observasi dan wawancara. Data dianalisis dengan metode deskriptif kualitatif. Peluang pengembangan ekowisata sangat besar karena areal HKm hutan lindung yang ada sudah memiliki potensi masing-masing. Di Gunungkidul, pengembangan ekowisata HKm dilakukan pada area Hutan Turunan/obyek wisata Watu Payung. Di Kulon Progo, pengembangan wisata di Kalibiru sudah menunjukkan hasil yang cukup baik dan ada beberapa embrio pengembangan ekowisata di lokasi Watu Gembel dan Puncak Dipowono. Seluruh obyek ekowisata tersebut mengandalkan potensi yang relatif hampir sama, yaitu pemandangan alam yang indah serta berbagai atraksi wisata lokal. Tantangan pada semua lokasi serupa, yaitu mencakup masalah finansial, infrastruktur dan kesiapan masyarakat setempat.
\end{abstract}

Kata Kunci: ekowisata, hutan kemasyarakatan, hutan lindung, masyarakat setempat, pengembangan ekowisata

\begin{abstract}
The development of community forests $(\mathrm{HKm})$ by the government aimed to empower and increase the income of forest communities. HKm can be undertaken in production forest or protect forest. The protect forest HKm farmer should have to improve forest's potential besides wood potential. One of it was tourism potential. This article aims to reveal the opportunities and challenges of tourism development in the area of protected forest HKm in Yogyakarta. The research was done in 2014 at HKm area in Kulon Progo and Gunungkidul. Data were collected by observation and interview. Data were analysed by qualitative descriptive method. The results showed that ecotourism development opportunities are very large because each area HKm existing protected forest already has the potential of each. In Gunung Kidul, ecotourism development conducted in the area of Turunan Forest/Watu Payung. In Kulon Progo, tourism development in Kalibiru has shown good results and there are some new development of ecotourism in Watu Gembel and Peak Dipowono. The whole object was rely on beautiful natural landscape and numerous tourism local attraction. Challenges at all locations, include financial problems, infrastructure and readiness of local communities.
\end{abstract}

Keywords: community forests, ecotourism, ecotourism development, local communities, protected forest.

\section{PENDAHULUAN}

Pengelolaan hutan di Indonesia telah mengalami perubahan paradigma, di mana awalnya terlalu berbasis pada negara (state based), khususnya di era orde baru, menjadi pengelolaan yang berbasis pada masyarakat (community based), yang dimulai di akhir masa pemerintahan orde baru hingga saat ini. Paradigma pembangunan sumber daya alam hutan dengan pendekatan community based ini disebut community forestry (kehutanan masyarakat). Sistem kehutanan masyarakat sebenarnya telah berkembang dengan baik di Indonesia dalam bentuk hutan rakyat, hutan adat, hutan keluarga, hutan desa maupun hutan kampung (Awang, 2003). Pemerintah melalui Kementerian Kehutanan merepresentasikan pemikiran kehutanan masyarakat melalui program Hutan Kemasyarakatan (HKm).

Sejak awal digulirkannya pada tahun 1995 hingga saat ini, program HKm mengalami berbagai perubahan peraturan demi perbaikan pelaksanaan di lapangan. Program HKm dilakukan di lahan hutan negara yang selanjutnya disebut lahan/areal HKm. 
Prinsip dari program $\mathrm{HKm}$ adalah pemberdayaan masyarakat dalam pengelolaan hutan. Masyarakat diberikan izin secara formal untuk mengelola lahan hutan negara melalui kelompok tani dan koperasi. Masyarakat dapat menanam tanaman pangan/MPTS di sela-sela tanaman kehutanan (kayu) dan kelak pada saat tanaman kayu sudah layak tebang, masyarakat akan mendapatkan manfaat bagi hasil kayu (khusus HKm kawasan hutan produksi).

Tanaman sela yang ditanam masyarakat di lahan $\mathrm{HKm}$ bervariasi tergantung dari kebiasaan setempat. Petani HKm Sesaot di Lombok menanam kopi dan buah-buahan di sela tanaman kayu (Galudra dkk., 2010). Jenis tanaman sela dominan pada HKm di desa Tanjung Alai, Riau, adalah karet, sungkai, durian, rambutan, kopi dan pinang (Rochmayanto dan Sasmita, 2005). HKm di Lampung lebih dominan dengan tanaman kopi, cokelat dan buah-buahan (Sanudin dkk., 2016). $\mathrm{HKm}$ di Gunungkidul mengusahakan tanaman palawija, rumput pakan ternak dan buah-buahan sebagai tanaman sela di antara tanaman kayu jati (Mulyadin dkk., 2016).

Program HKm dilaksanakan baik pada kawasan hutan produksi maupun hutan lindung. Sesuai dengan fungsi masing-masing hutan, maka terdapat perbedaan kegiatan yang boleh dan tidak boleh dilakukan oleh masyarakat (Anonim, 2014). Pada HKm hutan produksi, masyarakat dapat melakukan enam poin kegiatan antara lain: pemanfaatan kawasan, penanaman tanaman hutan berkayu, pemanfaatan jasa lingkungan, pemanfaatan hasil hutan bukan kayu, pemungutan hasil hutan kayu, dan pemungutan hasil hutan bukan kayu.

Pada HKm hutan lindung, masyarakat hanya dapat melaksanakan tiga poin kegiatan yaitu: pemanfaatan kawasan, pemanfaatan jasa lingkungan, dan pemungutan hasil hutan bukan kayu. Pemanfaatan kawasan pada hutan lindung dapat berupa budidaya tanaman obat, budidaya tanaman hias, budidaya jamur, budidaya lebah, penangkaran satwa liar, rehabilitasi satwa atau budidaya hijauan makanan ternak. Pemanfaatan jasa lingkungan adalah pemanfaatan potensi hutan lindung dengan tidak merusak lingkungan seperti ekowisata, wisata olah raga tantangan, pemanfaatan air dan perdagangan karbon. Pemungutan hasil hutan bukan kayu misalnya pemungutan rotan, madu, getah, buah, jamur atau sarang burung walet (Ginoga dkk., 2005; Dewi dkk., 2010).

Fandeli (2002), menyatakan bahwa hutan, apabila memiliki obyek alam yang menarik dapat dimanfaatkan untuk pengembangan ekowisata. Hal ini sesuai dengan kondisi hutan lindung yang dikelola oleh petani HKm di Yogyakarta. Tulisan ini bertujuan membahas peluang dan tantangan pengembangan ekowisata di areal $\mathrm{HKm}$ Yogyakarta, khususnya pada HKm hutan lindung.

\section{METODE PENELITIAN}

\section{Waktu dan Lokasi}

Penelitian dilaksanakan pada tahun 2014 di kawasan HKm Daerah Istimewa Yogyakarta, baik di Kabupaten Kulon Progo, Kabupaten Gunungkidul dan sebagian kecil Kabupaten Bantul, khususnya kawasan $\mathrm{HKm}$ yang berupa hutan lindung.

\section{Bahan dan Alat}

Bahan yang digunakan dalam penelitian ini adalah panduan daftar pertanyaan untuk informan. Panduan diperlukan agar pertanyaan tidak melebar. Alat yang digunakan dalam penelitian ini adalah alat tulis dan buku catatan serta kamera.

\section{Prosedur}

Penelitian diawali dengan melakukan kegiatan pengumpulan data. Data primer didapatkan melalui wawancara informan. Informan yang dimaksud adalah ketua kelompok tani $\mathrm{HKm}$, pengurus ekowisata dan staf Dinas Kehutanan setempat. Data sekunder diperoleh dari berbagai laporan dan dokumentasi dari kelompok tani maupun Dinas Kehutanan.

Analisis data dilakukan dengan menggunakan metode deskriptif kualitatif (Lambert and Lambert, 2012). Studi deskriptif kualitatif menggambarkan kondisi natural suatu lokus penelitian, menuju sebuah komitmen kondisi natural tersebut sampai pada tingkat yang lebih baik. Penyajian data dilakukan dalam bentuk uraian verbal berupa ringkasan padat dari isi informasi data. Data disajikan dari konteks yang luas ke konteks yang lebih sempit.

\section{HASIL DAN PEMBAHASAN}

\section{Kelompok Tani Sebagai Pengelola Kawasan HKm Hutan Lindung DIY}

Kawasan HKm hutan lindung (HKm-HL) di Daerah Istimewa Yogyakarta terdapat di Kabupaten Gunungkidul, Kabupaten Kulon Progo dan sebagian kecil di Kabupaten Bantul. Secara keseluruhan ada delapan kelompok tani pengelola HKm-HL yaitu tiga kelompok di HKm-HL Gunungkidul dan lima kelompok di HKm-HL Kulon Progo, seperti tersaji pada Tabel 1.

Areal HKm-HL di Gunungkidul terdapat di Dusun Turunan, Desa Girisuko, Kecamatan Panggang (KTH Sidomulyo I dan Sidomulyo III) dan di Dusun Nogosari, Desa Selopamiyoro, Kabu- 
Tabel 1. Kelompok tani HKm-HL di Daerah Istimewa Yogyakarta.

\begin{tabular}{l|l|l}
\hline \multicolumn{1}{c|}{ Kabupaten } & Nama Koperasi/Kelompok Tani & \multicolumn{1}{c}{ Lokasi } \\
\hline Gunungkidul & $\begin{array}{l}\text { Koperasi Rimba Lestari } \\
\text { (Kelompok Tani Sidomulyo I, } \\
\text { Sidomulyo III, Sidomulyo V) }\end{array}$ & $\begin{array}{l}\text { Dusun Turunan, Desa Girisuko, Kecamatan Panggang dan } \\
\text { Dusun Nogosari, Desa Selopamiyoro, Kabupaten Bantul. } \\
\text { Lahan HKm: petak 108 dan 109 RPH Bibal, BDH Panggang }\end{array}$ \\
\hline Kulon Progo & $\begin{array}{l}\text { Koperasi Mandiri, Koperasi } \\
\text { Menggerrejo, Koperasi Sido }\end{array}$ & $\begin{array}{l}\text { Kecamatan Kokap (Dusun Kalibiru, Dusun Soka, Dusun } \\
\text { Clapar, Desa Hargowilis) dan Kecamatan Pengasih (Dusun }\end{array}$ \\
& $\begin{array}{l}\text { Akur, Koperasi Suko Makmur, } \\
\text { Girinyono, Desa Sendangsari). }\end{array}$ & Lahan HKm: petak 28 dan 29 RPH Sermo, BDH Kulon Progo \\
\hline
\end{tabular}

Sumber: Analisis data sekunder, 2014.

paten Bantul (KTH Sidomulyo V). Ketiga kelompok tersebut, bersama lima kelompok HKm hutan produksi, tergabung dalam satu koperasi yaitu koperasi Rimba Lestari. Areal yang dikerjakan oleh ketiga kelompok HKm-HL tersebut berupa satu hamparan yaitu petak 108 dan $109 \mathrm{RPH}$ Bibal, BDH Panggang. Jenis tanaman pada areal HKm, untuk tanaman kayu: jati, mahoni dan sono; tanaman MPTS: nangka, mangga, sirsak; pakan ternak: rumput gajah dan gleresede; tanaman pangan/tumpangsari: jagung, kacang tanah, ketela pohon; tanaman bawah tegakan: empon-empon.

Adapun areal HKm-HL di Kulon Progo terdapat di dusun Kalibiru, Desa Hargowilis, Kecamatan Kokap (Koperasi Mandiri); dusun Soka, Desa Hargowilis, Kecamatan Kokap (Koperasi Menggerejo); dusun Clapar, Desa Hargowilis, Kecamatan Kokap (Koperasi Sidoakur); dusun Girinyono, Desa Sendangsari, Kecamatan Pengasih (Koperasi Suko Makmur dan Koperasi Rukun Makaryo). Areal kerja kelima kelompok tani ini saling berdekatan yaitu pada petak 28 dan $29 \mathrm{RPH}$ Sermo, BDH Kulon Progo. Jenis tanaman pada areal HKm, untuk tanaman kayu: jati, mahoni, kayu putih, akasia; tanaman MPTS: nangka, melinjo, petai, petai, kemiri, cengkih, kakao, mangga, jengkol, sirsak, sukun, rambutan, durian, kelengkeng; pakan ternak: rumput gajah dan gleresede; tanaman pangan/tumpangsari: jagung, kacang tanah, kentang kleci, ketela pohon; tanaman bawah tegakan: empon-empon.

Petani pengelola HKm-HL pada mulanya merupakan masyarakat sekitar hutan yang mempunyai masalah keterbatasan pemilikan lahan pertanian. Hasil pangan yang didapatkan dari lahan milik kurang, sehingga petani mengelola lahan hutan yang berdekatan dengan tempat tinggal. Jarak tempat tinggal dengan hutan relatif dekat, berkisar antara 50-1.000 meter. Setelah ada program HKm, barulah petani mengelola lahan hutan secara resmi dengan izin pemerintah.

Perkembangan lebih lanjut setelah tanaman kayu mulai besar, masyarakat mulai sulit melakukan penanaman tanaman sela. Hasil yang didapatkan dari tanaman pangan mulai turun sehingga pendapatan masyarakat berkurang. Agar tidak tergantung pada hutan, maka perlahan-lahan masyarakat mulai mengalihkan pemanfaatan hutan untuk tujuan lain yaitu pemanfaatan jasa lingkungan sebagai ekowisata.

The International Ecotourism Society (TIES) mengatakan bahwa ekowisata adalah suatu bentuk perjalanan wisata ke area alami yang dilakukan dengan tujuan mengkonservasi lingkungan dan melestarikan kehidupan dan kesejahteraan penduduk setempat (Wood, 2002). Ekowisata juga bertujuan belajar, mengagumi, menikmati pemandangan serta tumbuhan satwa liar, juga aspek budaya yang ada (Manu dan Kuuder, 2012). Perwujudan aspek budaya dapat berupa kontribusi pada konservasi alam dan warisan budaya termasuk aktivitas kerja penduduk lokal (Nicula dan Spanu, 2014). Tiga elemen penting yang harus ada dalam ekowisata adalah area alami, kegiatan konservasi lingkungan dan kesejahteraan penduduk lokal.

Ekowisata yang dikelola oleh komunitas masyarakat seperti petani $\mathrm{HKm}$, tidak hanya akan mampu memberdayakan penduduk lokal, namun juga memperkuat modal manusia dan modal sosial pada lokasi wisata yang berdampak pada generasi berikutnya untuk meneruskan pembangunan ekowisata (Auesriwong dkk., 2015).

\section{Potensi Wisata HKm-HL Kabupaten Gunungkidul (Watu Payung)}

Kelompok $\mathrm{HKm}$ yang mengelola hutan negara di Kabupaten Gunungkidul, berjumlah 35 kelompok. Sebagian besar mengelola hutan produksi dan hanya tiga kelompok yang mengelola hutan lindung, dengan jumlah total anggota kelompok sekitar seratus orang. Tiga kelompok ini dibantu dengan kelompok lainnya sedang mengembangkan obyek wisata Watu Payung. Deskripsi obyek wisata Watu Payung, peluang dan tantangan pengembangannya disajikan pada Tabel 2.

Objek wisata "Watu Payung" mengoptimalkan potensi air terjun, gua karst, keanekaragaman hayati, tebing-tebing yang indah dan pemandangan Sungai Oyo. Sebagai pelengkap dibangun jalur tracking, joglo, gardu pandang, kolam pemancingan dan kolam renang anak. Objek wisata Watu Payung 
Tabel 2. Deskripsi, peluang dan tantangan obyek ekowisata HKm-HL Gunungkidul

\begin{tabular}{|c|c|c|}
\hline Watu Payung/Hutan Turunan & Peluang & Tantangan \\
\hline $\begin{array}{l}\text { Areal hutan berbatasan dengan jurang dan } \\
\text { tebing karst deretan pegunungan Sewu, dengan } \\
\text { daya tarik wisata: } \\
\text { - Pemandangan perbukitan } \\
\text { - Panorama alam aliran sungai Oyo yang } \\
\text { mengalir dari Kabupaten Gunungkidul ke } \\
\text { wilayah Kabupaten Bantul } \\
\text { - Tempat hidup fauna endemik kera ekor } \\
\text { panjang } \\
\text { - Gua-gua alam } \\
\text { - Air terjun } \\
\text { - Batu yang menyerupai bentuk paying. } \\
\text { Kondisi areal wisata sudah terbuka, ada } \\
\text { bangunan penunjang seperti toilet, balai } \\
\text { pertemuan /joglo, mushola, dan peta rencana } \\
\text { pengembangan wisata }\end{array}$ & $\begin{array}{l}\text { - Watu Payung/Hutan } \\
\text { Turunan merupakan bagian } \\
\text { dari kawasan Geopark } \\
\text { Gunungsewu yang sudah } \\
\text { diputuskan masuk dalam } \\
\text { jaringan geopark } \\
\text { internasional sehingga akan } \\
\text { langsung dibina oleh } \\
\text { UNESCO } \\
\text { - Dukungan dari pemerintah } \\
\text { provinsi, pemerintah } \\
\text { kabupaten dan instansi } \\
\text { terkait } \\
\text { - Peluang wisata praktik } \\
\text { pengelolaan hutan untuk } \\
\text { konsumsi pelajar dan } \\
\text { mahasiswa }\end{array}$ & $\begin{array}{l}\text { - Menyeimbangkan tiga fungsi } \\
\text { geopark, yaitu edukasi, } \\
\text { konservasi dan pemberdayaan } \\
\text { masyarakat } \\
\text { - Pengetahuan masyarakat tentang } \\
\text { edukasi dan konservasi masih } \\
\text { harus ditingkatkan } \\
\text { - Akses menuju lokasi berupa } \\
\text { jalanan terjal } \\
\text { - Banyaknya objek wisata sejenis } \\
\text { yang sudah berkembang di } \\
\text { kabupaten Gunungkidul. }\end{array}$ \\
\hline
\end{tabular}

Sumber: Analisis data primer, 2014.

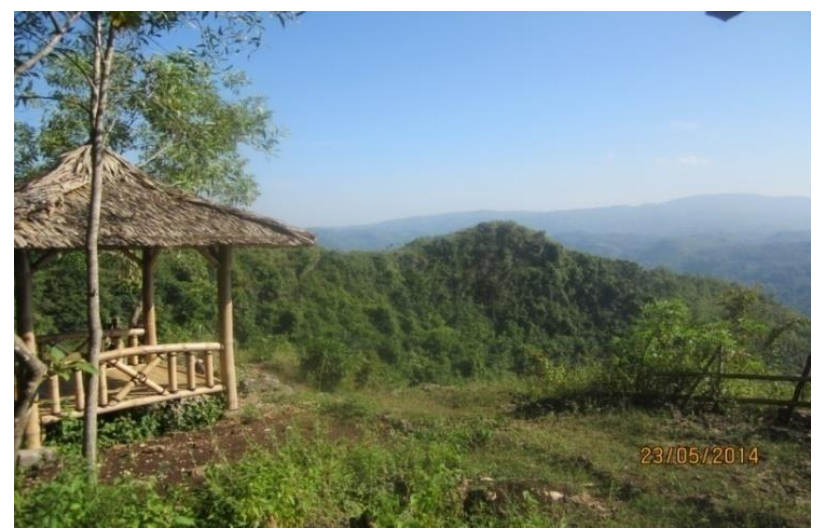

Gambar 1. Obyek Wisata Watu Payung

(seperti ditunjukkan pada Gambar 1) perlu dikelola secara serius karena merupakan salah satu dari tiga belas geoside (lokasi) di Gunungkidul yang merupakan bagian dari rencana pengembangan Global Geopark tiga kabupaten (Pacitan, Gunungkidul dan Wonogiri).

Kawasan Geopark adalah kawasan lindung berskala nasional yang mengandung situs warisan geologi penting dan memiliki daya tarik keindahan, kelangkaan sehingga dapat dikembangkan sebagai bagian dari konsep integrasi konservasi, pendidikan dan pengembangan ekonomi lokal (Anonim, 2004). Adapun yang harus diperhatikan adalah menyeimbangkan tiga fungsi geopark: edukasi, konservasi dan pemberdayaan masyarakat. Untuk fungsi yang ketiga yaitu pemberdayaan masyarakat sudah tak perlu diragukan lagi karena masyarakat sekitar sudah diberdayakan mengelola hutan Turunan sejak adanya konsep HKm. Menghidupkan fungsi edukasi dan konservasi dapat dilakukan dengan beberapa cara sebagai berikut:

1. Memberikan pendidikan dan pelatihan untuk masyarakat pengelola mengenai sejarah lokasi terkait posisinya dalam bagian geopark internasional, juga sejarah lokal pengelolaan hutan mulai dari saat masyarakat mengelola secara bebas, hingga munculnya konsep HKm sehingga masyarakat dapat mengelola hutan dengan izin dari pemerintah. Pengetahuan ini nantinya yang akan dibagikan kepada pengunjung sebagai salah satu bentuk fungsi edukasi.

2. Sebagai hutan lindung, fungsi konservasi dipertahankan dengan tidak melakukan banyak kegiatan yang mengubah bentang lahan. Pembangunan objek pelengkap wisata seperti joglo pertemuan, gardu pandang, toilet, warung dan arena bermain diusahakan sesedikit mungkin tanpa mengurangi kenyamanan.

\section{Potensi Wisata HKm-HL Kabupaten Kulon Progo}

Kelompok HKm Kulon Progo seluruhnya berjumlah tujuh kelompok. Dua kelompok mengelola hutan produksi dan lima kelompok mengelola hutan lindung. Ke tujuh kelompok tergabung dalam satu komunitas yang dinamakan komunitas Lingkar. Fungsi dari komunitas Lingkar adalah membahas semua kegiatan kelompok, termasuk kegiatan ekowisata.

Prospek pengembangan ekowisata HKm-HL di Kulon Progo sangat baik (Zunariyah, 2011), apalagi sebelumnya tak jauh dari lokasi, telah dibangun Waduk Sermo pada tahun 1996 yang juga menjadi salah satu tujuan wisata di Kulon Progo. Menurut Sudarmadji dan Widyastuti (2014), Waduk Sermo sebagai objek wisata mampu menyumbang Pendapatan Asli Daerah (PAD) hingga 140\%, namun perkembangan jumlah pengunjung belum menampakkan peningkatan yang berarti. Pengem bangan wisata lain di sekitar Waduk Sermo, berpeluang meningkatkan kunjungan wisata. 
Tabel 3. Deskripsi, peluang dan tantangan objek ekowisata HKm-HL Kulon Progo

\begin{tabular}{|c|c|c|}
\hline Wisata & Peluang & Tantangan \\
\hline $\begin{array}{l}\text { Kalibiru } \\
\text { Terletak di dusun Kalibiru, dikelola kelompok } \\
\text { tani Mandiri. } \\
\text { Daya tarik wisata: } \\
\text { - Pemandangan perbukitan dan waduk Sermo } \\
\text { - Udara sejuk pedesaan } \\
\text { - Sarana prasarana yang tersedia: } \\
\text { - Enam buah pondok dari kayu dan bambu, } \\
\text { joglo, } 4 \text { gardu pandang, } 1 \text { flying fox, kantor, } \\
\text { warung makanan, toilet }\end{array}$ & $\begin{array}{l}\text { - Saat ini sebagai andalan } \\
\text { daya tarik wisata hutan } \\
\text { kemasyarakatan di Kulon } \\
\text { Progo } \\
\text { - Aktivitas petani HKm di } \\
\text { sekitarnya masih berpeluang } \\
\text { untuk menjadi daya tarik } \\
\text { wisata, misalnya aktivitas } \\
\text { beternak atau menyadap } \\
\text { nira dan pembuatan gula. }\end{array}$ & $\begin{array}{l}\text { - Mempertahankan arus } \\
\text { wisatawan yang datang, } \\
\text { dengan sesedikit mungkin } \\
\text { mendirikan bangunan } \\
\text { permanen. } \\
\text { - Menambah daya tarik wisata } \\
\text { dengan menggali kembali } \\
\text { budaya masyarakat setempat. }\end{array}$ \\
\hline $\begin{array}{l}\text { Watu Gembel } \\
\text { Terletak di dusun Girinyono, dikelola } \\
\text { kelompok Sukomakmur. } \\
\text { Daya tarik wisata: } \\
\text { - Pemandangan perbukitan } \\
\text { - Air terjun } \\
\text { - Habitat rusa } \\
\text { Potensi masyarakat: mengembangkan pangan } \\
\text { olahan umbi-umbian (garut, ganyong, gembili) }\end{array}$ & $\begin{array}{l}\text { - Pengembangan penangkaran } \\
\text { rusa } \\
\text { - Jalur tracking } \\
\text { - Areal perkemahan } \\
\text { - Peluang wisata pendidikan } \\
\text { berupa pengolahan umbi- } \\
\text { umbian }\end{array}$ & $\begin{array}{l}\text { - Masih diperlukan dana untuk } \\
\text { pengembangan lokasi dan } \\
\text { sarana prasarana penunjang } \\
\text { (gardu pandang, toilet, pos) } \\
\text { - Saat musim kemarau air sungai } \\
\text { surut dan air terjun hilang, } \\
\text { sehingga daya tariknya } \\
\text { berkurang }\end{array}$ \\
\hline $\begin{array}{l}\text { Canting Mas/Puncak Dipowono } \\
\text { Terletak di dusun Clapar, dikelola kelompok } \\
\text { Sido Akur. } \\
\text { Daya tarik wisata: } \\
\text { - Pemandangan perbukitan, lembah, wisata } \\
\text { Kalibiru, Waduk Sermo, sampai laut Selatan } \\
\text { - Sarana prasarana yang tersedia: warung, } \\
\text { kantor, toilet, kursi/bangku bambu dan kayu } \\
\text { - Rencana pengembangan: akan dibangun } \\
\text { gardu pandang, flying fox. }\end{array}$ & $\begin{array}{l}\text { - Dilihat dari lokasi yang } \\
\text { lebih tinggi dari Kalibiru, } \\
\text { puncak Dipowono } \\
\text { berpeluang untuk } \\
\text { berkembang menjadi tujuan } \\
\text { wisata yang lebih indah } \\
\text { daripada Kalibiru yang } \\
\text { sudah lebih dahulu } \\
\text { berkembang } \\
\text { - Dapat dikembangkan } \\
\text { menjadi areal perkemahan }\end{array}$ & $\begin{array}{l}\text { - Mengembangkan areal HKm- } \\
\text { Hl sebagai areal wisata, tanpa } \\
\text { mengurangi fungsi hutan } \\
\text { lindung sebagai daerah resapan } \\
\text { air. } \\
\text { - Akses jalan masuk masih } \\
\text { berupa jalanan tanah yang } \\
\text { terjal } \\
\text { - Dana pengembangan lokasi } \\
\text { masih belum ada }\end{array}$ \\
\hline
\end{tabular}

Sumber: Analisis data primer, 2014.

Kegiatan ekowisata di HKm Kulon Progo mulai dilaksanakan tahun 2007 oleh Komunitas Lingkar dengan membangun wisata Kalibiru. Tahun 2014, dirintis pembangunan Puncak Dipowono, dan tahun 2015, dirintis pembukaan areal wisata Watu Gembel di dusun Sukomakmur. Deskripsi ketiga ekowisata HKm-HL dijelaskan pada Tabel 3. Pada Gambar 2 disajikan gambar spanduk wisata di obyek wisata ini.

Sejarah ekowisata HKm Kulon Progo dimulai dengan pembangunan areal wisata Kalibiru secara swadana dan swadaya sejak 2007. Mulai tahun 2008, melihat kesungguhan masyarakat, barulah bantuan dari pemerintah didapatkan untuk membangun sarana dan prasarana. Sarana dan prasarana yang dibangun antara lain: pembuatan jalan inspeksi (tracking), penataan kawasan, pembangunan enam buah pondok berbahan baku kayu dan bambu, empat buah gardu pandang, satu unit flying fox dan kantor sekretariat. Sejak tahun 2009, kegiatan wisata mulai berjalan dengan menggunakan tiket masuk sebesar Rp1.500,- dan naik menjadi Rp3.000,- di tahun 2014.

Bantuan dari pemerintah bukan hanya sebatas dana untuk pembangunan sarana dan prasarana

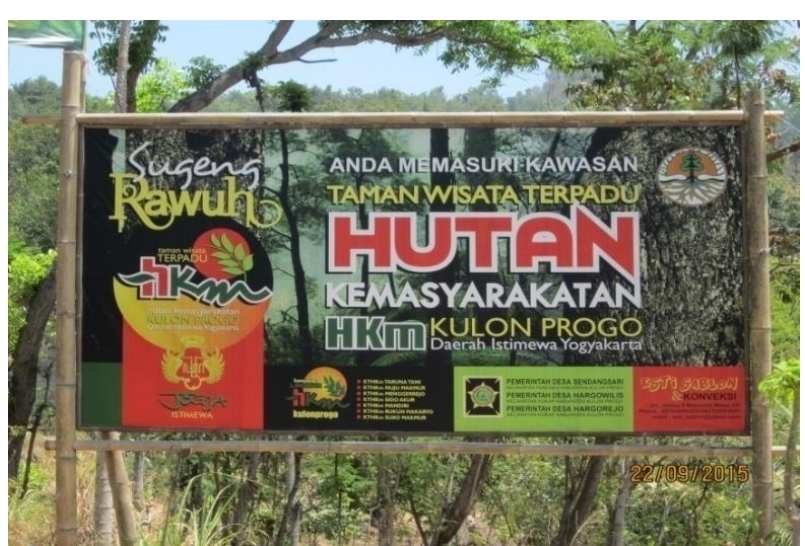

Gambar 2. Spanduk selamat datang di dusun Girinyono, di jalan masuk menuju Watu Gembel, Puncak Dipowono dan Kalibiru.

Obyek wisata, namun juga berupa pelatihan. Dinas Pariwisata daerah memberikan pelatihan pemandu wisata di desa/kampung wisata, dan juga pelatihan pelaku wisata budaya di desa wisata dan daerah tujuan wisata DIY. Dinas Kehutanan setempat tetap mengawal agar kegiatan wisata di areal $\mathrm{HKm}-\mathrm{HL}$ ini tidak sampai menyalahi peraturan dan tetap memperhatikan daya dukung lingkungan. Dinas Kehutanan juga memberikan bantuan berupa 
kegiatan studi banding ke areal ekowisata di daerah lain, untuk menambah wawasan pengelola obyek wisata Kalibiru.

Pengembangan dua obyek wisata lainnya dilakukan dengan cara yang sama. Ekowisata Watu Gembel dan Puncak Dipowono, dibuka secara swadana dan swadaya. Semua dilakukan dengan pendampingan petugas dari Dinas Kehutanan setempat. Pendampingan ini sangat diperlukan, untuk meminimalisir perbedaan pemahaman antara masyarakat dan petugas dalam memaknai kepentingan konservasi dan ekonomi (Satria, 2009; Mukhtar dkk., 2010), juga untuk mewujudkan stakeholder yang relevan, memiliki hak dan kemampuan untuk mengelola hutan secara bersama dan adil (Basuni, 2012).

\section{Pengembangan Ekowisata di Kawasan HKm Daerah Istimewa Yogyakarta}

Pengembangan ekowisata di areal HKm-HL diharapkan dapat meningkatkan perekonomian masyarakat secara umum, dan petani HKm secara khusus. Jika dikelola secara efektif, ekowisata dapat menimbulkan kesadaran masyarakat bahwa kawasan yang dilindungi dapat memberikan manfaat langsung bagi perubahan taraf hidup (Kuuder dkk., 2013). Hal ini sesuai dengan pengamatan penulis dan informasi Dinas Kehutanan setempat, bahwa masyarakat telah menyadari keberadaan hutan dapat memberi manfaat ekonomi bukan karena 'kayu'nya, tapi karena keberadaan hutan itu sendiri. Keberadaan wisata pada areal hutan, akan mengubah perilaku masyarakat yang awalnya permisif negatif terhadap sumberdaya hutan lestari, menjadi positif menjaga dan melindungi (Soekadri, 2000).

Mangunjaya (2006) mengatakan bahwa tantangan yang umum dihadapi sektor ekowisata adalah masalah infrastruktur, khususnya akses jalan ke lokasi wisata. Pada lokasi ekowisata HKm di Kulon Progo, karena telah dikembangkan sejak 2007, akses jalan menuju lokasi sudah tidak menjadi kendala. Kondisi jalan poros relatif sudah baik, walaupun letaknya jauh dari keramaian kota. Pada lokasi Puncak Dipowono, masih ada jalanan yang berupa jalan tanah terjal. Pada HKm-HL Gunungkidul, masih butuh perbaikan karena masih berupa jalan tanah dan berbatu.

Tantangan yang lebih serius dari ekowisata khususnya ekowisata yang lokasinya berstatus hutan lindung, adalah mempertahankan daya dukung lingkungan agar tidak rusak. Karena bagaimanapun interaksi lingkungan dengan masyarakat di luar lingkungan itu (wisatawan luar) pasti menimbulkan dampak. Secara khusus, areal HKm sangat tergantung dari izin usaha yang telah disepakati. Izin usaha pemanfaatan $\mathrm{HKm}$ yang didapatkan kelompok adalah selama 35 tahun dan dapat diperpanjang. Klausul jangka waktu izin dan mekanisme perpanjangan yang belum jelas ini merupakan hambatan/tantangan dalam mewujudkan areal HKm-HL sebagai areal wisata yang berkelanjutan.

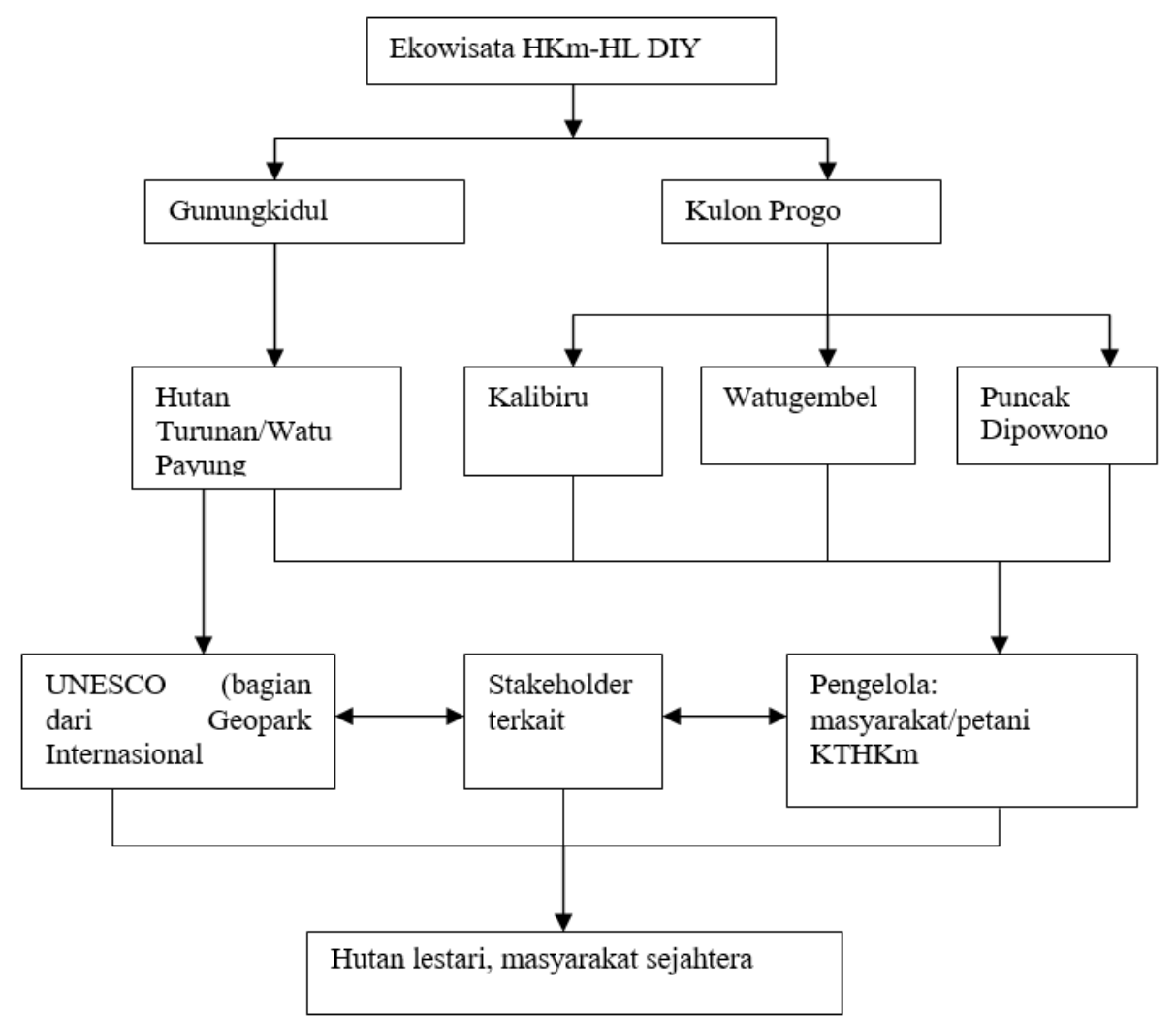

Gambar 3. Bagan pengelolaan ekowisata HKm-HL DIY 
Tantangan yang lain adalah menambah daya tarik wisata khas kedaerahan atau keunggulan lokal (Hasiholan, 2015). Apa yang dianggap biasa oleh penduduk desa, bisa menjadi obyek wisata yang menarik perhatian penduduk kota. Kegiatan pengelolaan hutan, praktik mengolah umbi-umbian menjadi kuliner khas, sehari beternak sapi, adalah contoh kegiatan khas pedesaan yang dapat dikemas dalam satu paket ekowisata. Itu perlu dikembangkan, dengan mengurangi atraksi modern yang membutuhkan investasi besar (Haryanto, 2013).

Petani HKm sebagai pengelola, perlu secara berkelanjutan diberikan pelatihan kepariwisataan dan pengetahuan konservasi hutan. Kerjasama pengelola dengan pihak terkait sangat penting untuk mendukung keberlanjutan ekowisata HKmHL. Gambar 3 menunjukkan bagan pengelolaan wisata HKm-HL di Daerah Istimewa Yogyakarta. Masyarakat adalah pengelola utama, namun harus selalu berkoordinasi dengan pihak lain untuk tujuan yang sama yaitu hutan lestari dan masyarakat sejahtera. Hal ini juga berlaku di beberapa area ekowisata lainnya (Setyadi dkk., 2012).

Pengembangan ekowisata akan berhasil jika seluruh pihak terkait berpedoman pada tiga hal yaitu: area alami harus sesedikit mungkin mengalami sentuhan 'pembangunan', sebaliknya perlu dikembangkan sesuatu yang alami dan khas daerah setempat; adanya areal wisata yang sudah berkembang tidak boleh mengesampingkan kegiatan konservasi lingkungan yang harus selalu dilakukan untuk menjaga kelestarian hutan lindung; penduduk lokal atau dalam hal ini anggota kelompok tani HKm-HL harus menjadi penerima pertama manfaat dari kegiatan wisata yang dikembangkan.

\section{KESIMPULAN}

Peluang pengembangan ekowisata HKm-HL Daerah Istimewa Yogyakarta sangat besar, karena ada potensi-potensi yang masih dapat dikembangkan menjadi ekowisata yang berkelanjutan. Ekowisata yang telah berkembang tersebut antara lain objek wisata Watu Payung, di Gunungkidul; dan Kalibiru, Watu Gembel serta Puncak Dipowono di Kulon Progo.

Tantangan pengembangan ekowisata mencakup tantangan dari segi finansial, infrastruktur dan kesiapan masyarakat setempat. Secara finansial, masyarakat masih tergantung pada bantuan pemerintah, walaupun ada kesediaan dari masyarakat untuk secara swadana dan swadaya membiayai sebagian besar kegiatan pembukaan lahan dan pembangunan infrastruktur awal. Dari sisi infrastruktur, walaupun sebagian akses jalan sudah baik, masih perlu diperbaiki juga infrastruktur lainnya. Dari sisi kesiapan masyarakat setempat, masih perlu dukungan pelatihan kepariwisataan, kelembagaan dan manajemen agar dapat semakin paham mengelola suatu area ekowisata yang sehat, yang seimbang antara perwujudan kelestarian lingkungan dan peningkatan kesejahteraan masyarakat.

\section{DAFTAR PUSTAKA}

Anonim, 2004. Operational Guideline for National Geoparks Seeking Unesco's Assistance. Network of National Geoparks Seeking Unesco's Assistance. Paris.

Anonim, 2014. Peraturan Menteri Kehutanan P.88/Menhut-II/2014 Hutan Kemasyarakatan. 7 Oktober 2014. Kementerian Kehutanan. Jakarta.

Auesriwong, A., Nilnoppakun, A. and Parawech, W., 2015. Integrative Participatory Community Based Ecotourism at Sangkhom District, Nong Khai Province, Thailand. Procedia Economics and Finance, 23(1): 778 -782 .

Awang, S.A., 2003. Politik Kehutanan Masyarakat. Center for Critical Social Studies dan Kreasi Wacana. Yogyakarta.

Basuni, S., 2012. Kaidah Pengelolaan Hutan Lindung Lestari. Workshop Penyusunan Rancangan Standar Nasional Indonesia (RSNI) Pengelolaan Hutan Lestari 11 September 2012. Fakultas Kehutanan Institut Pertanian Bogor.

Dewi, I.N., Rizal A.H.B., dan Kusumedi, P., 2010. Implementasi Peraturan tentang Pengelolaan Hutan Lindung: Studi Kasus di Kabupaten Pangkep dan Kabupaten Maros, Sulawesi Selatan. Jurnal Analisis Kebijakan Kehutanan, 7(3):195-209.

Fandeli, C., 2002. Perencanaan Kepariwisataan Alam. Penerbit Fakultas Kehutanan Universitas Gadjah Mada. Yogyakarta.

Galudra, G., Buana, Y dan Khususiyah, N., 2010. Mau Melangkah ke Mana Pengelolaan Hutan Sesaot? Brief No. 09 Policy Analysis Unit. World Agroforestry Center. Bogor.

Ginoga, K., Lugina, M dan Djaenudin, D., 2005. Kajian Kebijakan Pengelolaan Hutan Lindung. Jurnal Penelitian Sosial dan Ekonomi, 2(2):203-231

Haryanto, J.T., 2013. Implementasi Nilai-Nilai Budaya, Sosial, dan Lingkungan Pengembangan Desa Wisata di Provinsi Yogyakarta. Jurnal Kawistara, 3(1):1-11 
Hasiholan, L.B., 2015. Peran Enterpreneur Batik Semarang dalam Mengangkat Keunggulan Lokal Menyambut MEA 2015. Jurnal Ekonomi dan Bisnis Kontemporer, 1(1):42-54.

Kuuder, C.J.W., Bagson, E and Aalangdong, I.O., 2013. Livelihood Enhancement through Ecotourism: A Case of Mognori Ecovillage near Mole National Park, Damongo, Ghana. International Journal of Business and Social Science, 4(4):128-137.

Lambert, V.A., dan Lambert, C.E., 2012. Editorial: Qualitative Descriptive Research: An Acceptable Design. Pacific Rim International Journal of Nursing Research, 16(4):255-256

Mangunjaya, F.M., 2006. Hidup Harmonis Dengan Alam: Esai-esai Pembangunan Lingkungan, Konservasi dan Keanekaragaman Hayati Indonesia. Yayasan Obor Indonesia. Jakarta.

Manu, I dan Kuuder, C.J.W., 2012. CommunityBased Ecotourism and Livelihood Enhancement in Sirigu, Ghana. International Journal of Humanities and Social Science, 2(18):97-108.

Mukhtar, Soemarno dan Hidayat, K., 2010. Pengelolaan Program Hutan Kemasyarakatan Berbasis Kearifan Lokal: Studi Kasus di Kawasan Hutan Lindung Sesaot Lombok Barat. Jurnal Wacana, 13(1):132-151.

Mulyadin, R.M., Surati dan Ariawan, K., 2016. Kajian Hutan Kemasyarakatan sebagai Sumber Pendapatan: Kasus di Kabupaten Gunungkidul, Yogyakarta. Jurnal Penelitian Sosial dan Ekonomi Kehutanan, 13(1):13-23

Nicula, V. and Spanu, S., 2014. Ways of Promoting Cultural Ecotourism for Local Communities in Sibiu Area. Procedia Economics and Finance, 16 (1):474-479.
Rochmayanto, Y dan Sasmita, T., 2005. Peluang dan Hambatan Pengembangan HKm di Koto Panjang, Riau : Pendekatan Sosiologis. Jurnal Penelitian Sosial dan Ekonomi Kehutanan, 2(3):279-289.

Sanudin, Awang, S.A., Sadono, R dan Purwanto, RH., 2016. Perkembangan Hutan Kemasyarakatan di Provinsi Lampung. Jurnal Manusia dan Lingkungan, 23(2):276-283

Satria, D., 2009. Strategi Pengembangan Ekowisata Berbasis Ekonomi Lokal dalam Rangka Program Pengentasan Kemiskinan di Wilayah Kabupaten Malang. Journal of Indonesian Applied Economics, 3(1):37-47.

Setyadi, I.A., Hartoyo, Maulana, A dan Muntasib E.K.S.H., 2012. Strategi Pengembangan Ekowisata di Taman Nasional Sebangau Kalimantan Tengah. Jurnal Manajemen dan Agribisnis, 9(1):1-12

Soekadri, 2000. Perilaku Masyarakat Pemukim Kawasan Hutan Lindung di Kabupaten Kulon Progo Propinsi Daerah Istimewa Yogyakarta. Majalah Geografi Indonesia, 14(1):1-12.

Sudarmadji dan Widyastuti, 2014. Dampak dan Kendala Wisata Waduk Sermo dari Aspek Lingkungan Hidup dan Risiko Bencana. Jurnal Teknosains, 3(2):142-157.

Wood, M.E., 2002. Ecotourism: Principles, Practices \& Policies For Sustainability. United Nations Environment Programme, The International Ecotourism Society, United Nations Publication. Paris.

Zunariyah, S., 2011. Pengembangan Institusi Pengelola Hutan Kemasyarakatan. Jurnal Sosiologi Dilema, 27(2):159-168. 